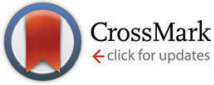

Cite this: Chem. Commun., 2015, 51, 14235

Received 10th July 2015,

Accepted 30th July 2015

DOI: $10.1039 / c 5 c c 05737 j$

www.rsc.org/chemcomm

\section{Sterically geared tris-thioureas; transmembrane chloride transporters with unusual activity and accessibility $\dagger$}

\author{
Hennie Valkenier, ${ }^{* a}$ Christopher M. Dias, ${ }^{a}$ Kathryn L. Porter Goff, ${ }^{a}$ Ondřej Jurček, \\ Rakesh Puttreddy, ${ }^{b}$ Kari Rissanen ${ }^{\mathrm{b}}$ and Anthony P. Davis ${ }^{\star a}$
}

Tris- $N$-arylthioureas derived in one step from 1,3,5-tris(aminomethyl)2,4,6-triethylbenzene are remarkably effective anion carriers. With optimised aryl substituents their activities come close to the best currently known, suggesting that they might find use as readily available standards in anion transport research.

Transmembrane anion carriers ${ }^{1}$ have potential as tools for biomedical research, as anti-cancer agents, ${ }^{2}$ and as treatments for channelopathies caused by defective or absent chloride channels (e.g. cystic fibrosis). ${ }^{3}$ Recent work from this ${ }^{4,5}$ and other ${ }^{6,7}$ laboratories has shown that powerful anionophores can be developed, and that systems featuring preorganised ureas or thioureas are especially effective. However, preorganisation may be costly in preparative terms. Systems such as cholapods $\mathbf{1}^{5,8}$ and diureidodecalins $2^{5,9}$ (Fig. 1) show outstanding performance but require fairly lengthy syntheses.

To complement these highly active anion carriers, there is a need for anionophores which are effective but also readily accessible. Such compounds can lower the barrier to exploitation, and can also serve as standards for optimisation studies. We have previously shown that extreme preorganisation and anion affinities are not necessarily required for high transport activity. The cyclohexane-based systems $\mathbf{3}$ and $\mathbf{4}$ (Fig. 1) are accessible in just $4-5$ steps from commercial starting materials. ${ }^{10}$ Compared to $\mathbf{1}$ and $\mathbf{2}$ these carriers have much more conformational freedom. However, while this was reflected by lower affinities for chloride, some examples were found to be surprisingly effective as chloride transporters. Indeed the most powerful $(\mathbf{4 S F} 2)^{11}$ is among the most effective anionophores known, and just 8 times less active than the best available. ${ }^{5}$

\footnotetext{
${ }^{a}$ School of Chemistry, University of Bristol, Cantock's Close, Bristol BS8 1TS, UK. E-mail: Hennie.Valkenier@bristol.ac.uk, Anthony.Davis@bristol.ac.uk

${ }^{b}$ University of Jyväskylä, Department of Chemistry, Nanoscience Center, P.O. Box 35, FI-40014, Finland

$\dagger$ Electronic supplementary information (ESI) available: Experimental details of the synthesis, binding and transport studies, modelling, and crystal structure. CCDC 1411525. For ESI and crystallographic data in CIF or other electronic format see DOI: $10.1039 / \mathrm{c} 5 \mathrm{cc} 05737 \mathrm{j}$
}

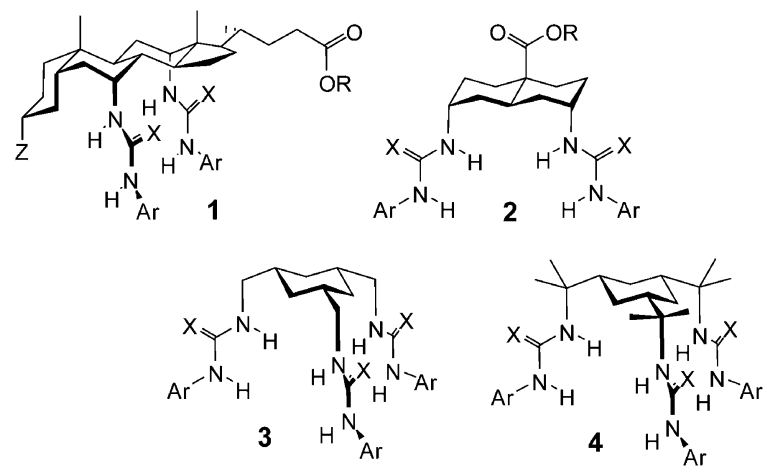

$X=O, S \quad Z=O A c, \mathrm{NHCOCF}_{3}$

Fig. 1 Structures of previously reported anion transporters. A range of groups Ar have been used, most typically those shown in Scheme 1.
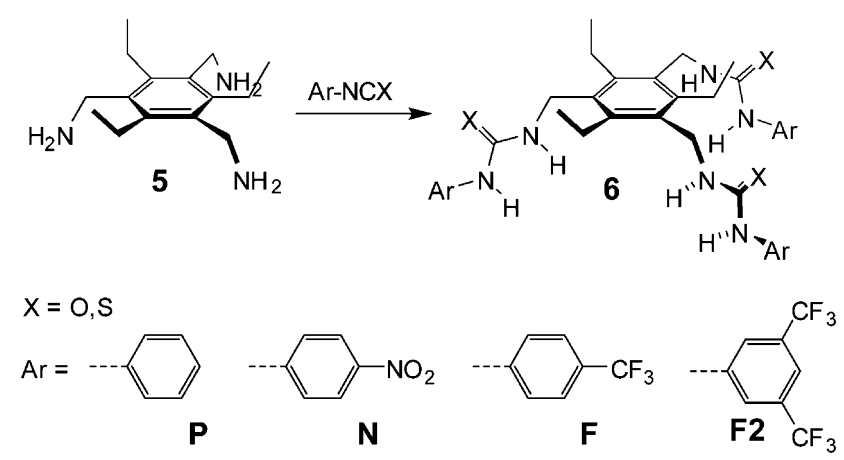

Scheme 1 Synthesis and structures of tris(thio)ureas 6 .

While $\mathbf{3}$ and $\mathbf{4}$ are easy to prepare, they still require several steps. For widespread use, a single-step synthesis is clearly preferable. We therefore turned to the tris(thio)ureas 6 (Scheme 1). These bear similarities to $\mathbf{3}$ and $\mathbf{4}$, but are accessible directly from the commercially available triamine $\mathbf{5}$ by reaction with iso(thio)cyanates. Scaffold $\mathbf{5}$ is widely used in supramolecular chemistry because of the preorganisation afforded by steric gearing (the tendency of substituents to alternate in direction, driven by 
a)

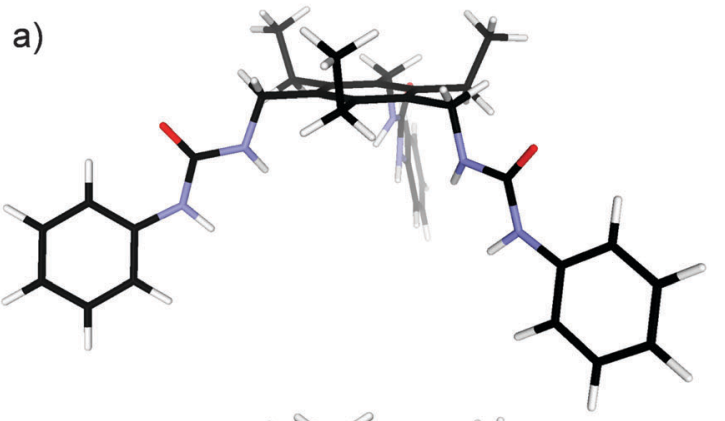

b)

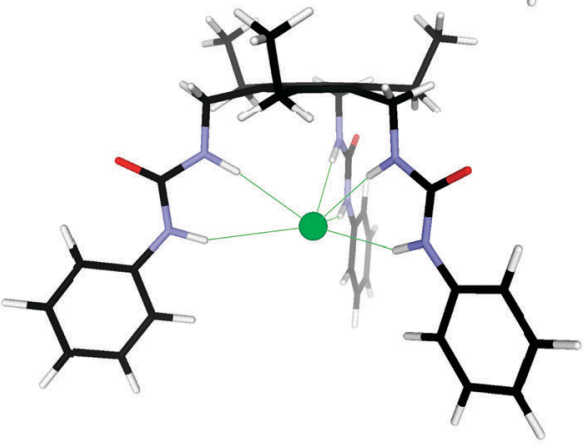

c)

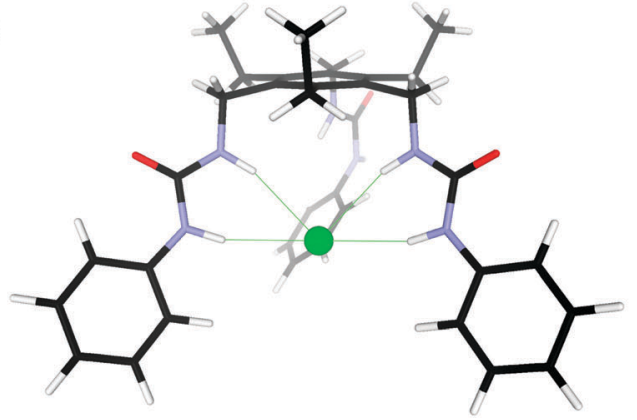

Fig. 2 Molecular models of tris-urea 60P and potential chloride complexes, energy-minimised using ab initio calculations (Hartree-Fock, 6-31+G* basis set). (a) Free receptor in ground state conformation. (b) $C_{3 v}$ structure of $60 P$. $\mathrm{Cl}^{-}$. Hydrogen bonds (green) are $3 \times 2.7 \AA$ and $3 \times 3.1 \AA$. (c) Alternative structure of $6 \mathrm{OP} \cdot \mathrm{Cl}^{-}$in which chloride is bound by two urea groups via four $\mathrm{NH}$... $\mathrm{Cl}^{-} \mathrm{H}$-bonds (all $2.6 \AA$ ). The third urea group features an $E \mathrm{CONH}$ unit which permits a weak $\mathrm{CH}_{\cdots} \ldots \mathrm{Cl}^{-}$interaction. For further details of the calculations see ESI. $\dagger$

steric bulk). ${ }^{12}$ Ureas and thioureas based on 5 have been applied in several areas of supramolecular chemistry, ${ }^{13}$ but the simple derivatives $\mathbf{6}$ have not previously been tested as anion carriers. Here we report that these compounds show remarkable transport activity, and are well suited to serve as powerful but accessible anionophores for anion transport research.

A precondition for anionophore activity is the ability to bind the target substrate. For biologically relevant anion transport the major target is chloride, so the potential for $\mathbf{6}$ to act as a chloride receptor was studied computationally. ${ }^{14}$ Calculations on free receptor $60 \mathrm{OP}$ predicted a ground state with converging $\mathrm{NH}$ groups (Fig. 2a), free of counterproductive $\mathrm{NH} \cdots \mathrm{O}$ interactions. Although the $\mathrm{NH}$ groups are spread quite widely, addition of $\mathrm{Cl}^{-}$ resulted in contraction of the binding site to yield multiple $\mathrm{NH} \cdots \mathrm{Cl}^{-}$ hydrogen bonds. Two binding geometries were identified, a $C_{3 \mathrm{v}}$ structure with a centrally placed $\mathrm{Cl}^{-}$and six $\mathrm{NH} \cdots \mathrm{Cl}^{-} \mathrm{H}$-bonds
(Fig. 2b), and a second structure with four shorter $\mathrm{NH}^{\cdots} \cdot \mathrm{Cl}^{-} \mathrm{H}-$ bonds involving two of the urea groups (Fig. 2c). The two structures were close in energy, the $C_{3 \mathrm{v}}$ version being the more stable by $1.1 \mathrm{~kJ} \mathrm{~mol}^{-1}$.

Tris(thio)ureas 6 were synthesised by treatment of $\mathbf{5}$ with 3.3-4 equivalents of the appropriate isothiocyanate or isocyanate overnight at room temperature in either THF or DMF. Thioureas 6SP, 6SN, 6SF, and 6SF2 were obtained in $54-88 \%$ yields, and urea 6 OF2 in $32 \%$ yield. Detailed synthetic procedures and full characterisation data are given in the ESI. $\dagger$

The binding properties of 6 towards chloride in DMSO- $\mathrm{d}_{6} /$ $\mathrm{H}_{2} \mathrm{O}(200: 1)$ were studied by ${ }^{1} \mathrm{H}$ NMR titrations, employing tetrabutylammonium chloride as substrate. Receptor $\mathrm{NH}$ signals shifted downfield as expected, and smaller movements were also observed for aromatic $\mathrm{CH}$ signals. The changes were consistent with $1: 1$ binding during the early part of the titrations but showed deviations towards the end, suggestive of weak binding of a second chloride ion. The data were therefore analysed using a $1: 1+1: 2$ (host: guest) binding model ${ }^{15}$ to give the binding constants $K_{\mathrm{a}}$ listed in Table 1. Affinities in $\mathrm{CHCl}_{3}$ were mostly too high for measurement by ${ }^{1} \mathrm{H}$ NMR so, where solubility permitted, they were obtained by the extraction method described previously (see Table 1). ${ }^{16}$ In the case of the weakest receptor 6 SP the ${ }^{1} \mathrm{H}$ NMR titration method could be applied and gave $K_{\mathrm{a}}=1.5 \times 10^{4} \mathrm{M}^{-1}$, close to value obtained by extraction. For this titration the signal movements fitted well to a $1: 1$ binding model, suggesting that the stoichiometry may be solvent dependent.

The affinities measured for $\mathbf{6}$ make interesting comparisons to those published earlier for $\mathbf{3}$ and $\mathbf{4}$ (see Table 1). In wet DMSO, new benzene-based 6 proved stronger than the desmethyl cyclohexane system 3 , but slightly weaker than the hexamethyl analogues 4 . This is unsurprising given the distortion predicted for $\mathbf{6}$ on binding chloride (Fig. 2), and the absence of similar strain for 4 . However in chloroform the position is reversed, to the extent that $\mathbf{6 S F 2}$ binds $\mathrm{Et}_{4} \mathrm{~N}^{+} \mathrm{Cl}^{-} \sim 20$ times more strongly than $\mathbf{4 S F 2}$. This is more difficult to explain, but one possibility involves intramolecular interactions in the free receptors. While the benzene-based scaffold holds the binding groups apart, the cyclohexane-based systems are more compact and might allow weak interactions between the (thio)urea groups (favouring non-binding conformations). This factor might be more important in chloroform than in DMSO, which solvates the binding groups more effectively. It is also notable that the affinities in chloroform are very sensitive to the nature of the aryl substituents; for example, $\mathbf{6 S F 2}$ was found to be $40 \times$ more powerful than $\mathbf{6 S F}$. The cyclohexane-based receptors 4 behave similarly (compare $\mathbf{4 S F 2}$ and $\mathbf{4 S F}$ in Table 1), but the differences for the bis-(thio)ureido cholapods $\mathbf{1}$ and decalins $\mathbf{2}$ were much smaller (for example, a factor of 4 for $2 \mathrm{SF} 2 v s$. $2 \mathrm{SF}$, with $\mathrm{R}=\mathrm{Et}^{5}$ ). This could suggest that all three thiourea groups of $\mathbf{6}$ are involved in binding in chloroform.

The performance of the triethylbenzene-based tris[(thio)ureas] 6 as anion transporters was tested using the previously-reported lucigenin assay. ${ }^{17}$ Large unilamellar vesicles (LUVs, $200 \mathrm{~nm}$ ) of POPC and cholesterol $(7: 3)$ were formed with the transporter preincorporated in the membrane (at transporter:lipid ratios of $1: 2500$ or $1: 25000$ ) and suspended in an aqueous solution of sodium nitrate (225 mM both interior and exterior). The aqueous 
Table 1 Binding and transport data for tris(thio)ureas 3, 4 and 6

\begin{tabular}{|c|c|c|c|c|c|c|c|}
\hline \multicolumn{3}{|c|}{ Compound } & \multicolumn{2}{|c|}{ Binding to $\mathrm{Bu}_{4} \mathrm{~N}^{+} \mathrm{Cl}^{-}$in DMSO- $\mathrm{d}_{6} / \mathrm{H}_{2} \mathrm{O}(200: 1)^{b}$} & \multirow{2}{*}{$\frac{\text { Binding to } \mathrm{Et}_{4} \mathrm{~N}^{+} \mathrm{Cl}^{-} \text {in } \mathrm{CHCl}_{3}{ }^{e}}{K_{\mathrm{a}}\left(\mathrm{M}^{-1}\right) \text { (apparent) }}$} & \multicolumn{2}{|c|}{ Chloride-nitrate exchange in LUVs } \\
\hline Scaffold & $\mathrm{x}$ & $\mathrm{Ar}$ & $K_{\mathrm{a}, 1: 1}{ }^{c}\left(\mathrm{M}^{-1}\right)$ & $K_{\mathrm{a}, 1: 2}{ }^{c, d}\left(\mathrm{M}^{-1}\right)$ & & $t_{1 / 2}^{f}(\mathrm{~s})$ & Specific initial rate $[I]^{g}\left(\mathrm{~s}^{-1}\right)$ \\
\hline 6 & $\mathrm{~S}$ & $\mathrm{P}$ & 130 & 7 & $1.9 \times 10^{4}$ & 510 & $<5$ \\
\hline 6 & $S$ & $\mathrm{~F}$ & 300 & 10 & $1.5 \times 10^{7}$ & 81 & 56 \\
\hline 6 & $S$ & $\mathrm{~F} 2$ & 450 & 10 & $6.8 \times 10^{8}$ & 19 & 350 \\
\hline 6 & $\mathrm{O}$ & F2 & 390 & 25 & n.d. & 110 & 50 \\
\hline $3^{a}$ & $\mathrm{~S}$ & F2 & 100 & & $2.4 \times 10^{6}$ & 160 & 14 \\
\hline $4^{a}$ & $\mathrm{O}$ & F2 & 390 & & n.d. & 25 & 140 \\
\hline
\end{tabular}

n.d. $=$ not determined due to low solubility of the compound in chloroform. ${ }^{a}$ Compounds reported previously. ${ }^{10 b 1} \mathrm{H}$ NMR titrations at $298 \mathrm{~K}$. ${ }^{c}$ Obtained from fitting of all data points to a $1: 1+1: 2$ binding model in HypNMR2008. ${ }^{d} K_{\mathrm{a}}$ for addition of second substrate to $1: 1$ complex. ${ }^{e}$ Obtained by extraction from water into chloroform at $303 \mathrm{~K}$, as described in ref. 16 . These values are considered apparent due to uncertainties concerning receptor aggregation state, complex stoichiometry etc. ${ }^{f}$ Obtained from fits $(0-500 \mathrm{~s})$ of $F_{0} / F$ for transporter: lipid $=1: 2500$ to a single exponential function. ${ }^{g}$ Specific initial rate $[I]$ : initial slope of $F_{0} / F v s$. time $t$, divided by the transporter/lipid ratio in the vesicle bilayers and averaged over a range of experiments at different ratios; see ESI for details.

solution inside the vesicles also contained the halide sensitive dye lucigenin, of which the fluorescence intensity was monitored over time in a fluorescence spectrometer. Upon addition of sodium chloride $(25 \mathrm{mM})$ to the vesicles the anion transporter exchanged external chloride for internal nitrate. The resulting increase in internal chloride concentration in the vesicles was observed as a decrease in the fluorescence intensity (Fig. 3, see ESI $\dagger$ for experimental details). The fluorescence decay data were analysed to give

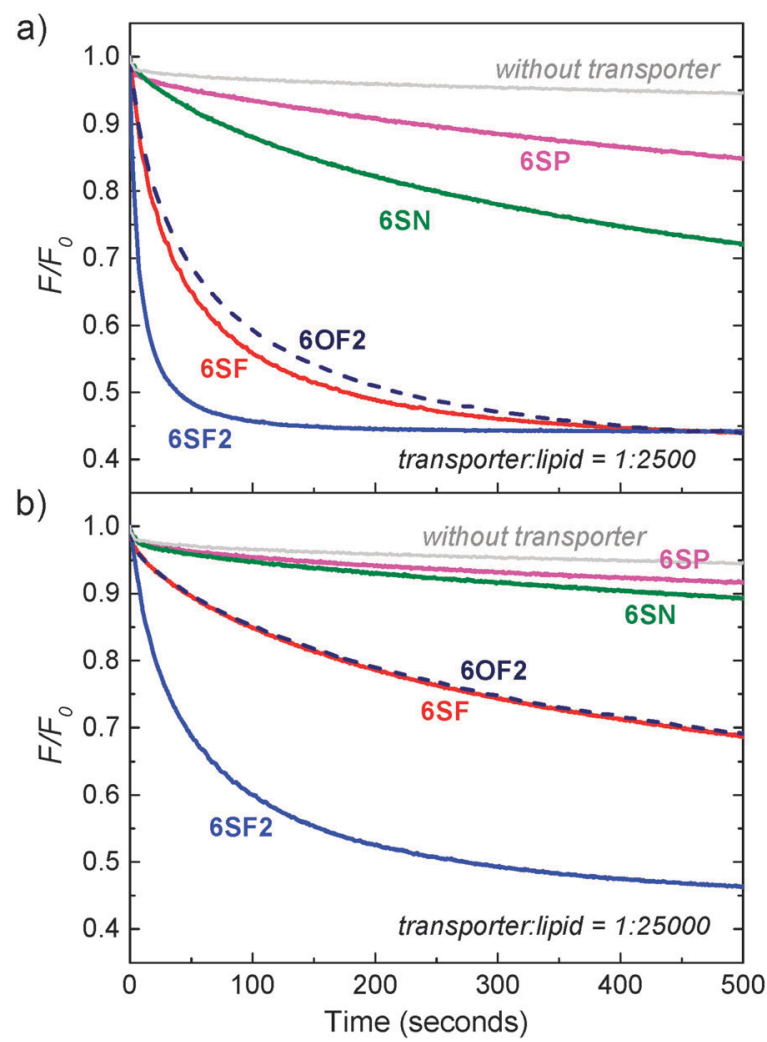

Fig. 3 Chloride/nitrate exchange by anionophores 6 in $200 \mathrm{~nm}$ POPC/ cholesterol $(7: 3)$ vesicles, as followed by the lucigenin method. (a) Fluorescence decay traces at transporter : lipid $=1: 2500$. (b) Fluorescence decay traces at transporter: lipid $=1: 25000$. approximate half-lives $\left(t_{1 / 2}\right)$ for chloride-nitrate exchange, and specific initial rates $([I])^{5}$ as listed in Table 1 . The quantity $[I]$, defined in Table 1, is independent of receptor loading and provides a method for comparing transporters of widely different activities. The analysis methods are detailed in previous work ${ }^{5}$ and in the ESI. $\dagger$

The results in Table 1 show that receptors 6 can indeed serve as powerful anion carriers. ${ }^{18}$ In line with previous work, ${ }^{4-9}$ the rates are strongly dependent on the nature of the binding groups (thiourea $>$ urea) and the aryl substituent (electron-withdrawing groups being more effective). The most powerful variant, 6SF2, which was also found to have the strongest affinity for chloride, induced chloride-nitrate exchange with a half-life of only $19 \mathrm{~s}$ when preincorporated at 1:2500 transporter : lipid ratio (see also Fig. 3a), and a specific initial rate of $350 \mathrm{~s}^{-1}$. Urea analogue $60 \mathrm{~F} 2$ and (trifluoromethyl)phenyl-substituted 6SF are 6-7 times less active than 6SF2. The $p$-nitrophenyl compound $\mathbf{6 S N}$ is less effective than might have been expected based on previous work and its high chloride affinity, but this may be due to poor solubility in membranes (chloroform solubility is very low). The low activity of 6SP presumably results from its weak affinity for chloride.

The key comparisons in Table 1 are between transport activities for $\mathbf{6}$ and cyclohexane-based analogues 4 . Although transporters 4 are generally more powerful than $\mathbf{6}$, the differences are small. Thus, 6SF2 possesses roughly $70 \%$ the activity of $\mathbf{4 S F} 2$, as measured by both $t_{1 / 2}$ and $[I]$. Given that $\mathbf{4 S F 2}$ was the most powerful transporter reported from our laboratory at the time of publication (early 2014), the performance of $\mathbf{6 S F 2}$ is quite impressive. Further advances have since been made, ${ }^{5}$ but $\mathbf{6 S F 2}$ is still within $\sim 1$ order of magnitude of the most active anionophore available (see Fig. 4).

The combination of high activity and outstanding accessibility suggests that $\mathbf{6 S F 2}$ could find widespread use in studies of anion transport. For example, it is well suited to serve as a standard anionophore for groups who wish to implement vesicle-based measurements, and as a comparison for new designs. Alternatives might be found among the tripodal tris-thioureas derived from tris(2-aminoethyl)amine (tren), which are also highly active. ${ }^{6}$ However, the tren-based systems are complementary in that they are less lipophilic and can transport protons as well as anions under some conditions. 


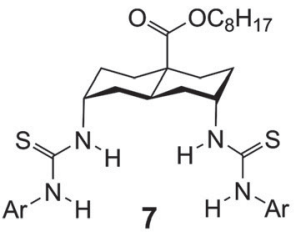

$\left[/=3800 \mathrm{~s}^{-1}\right.$

9 synthetic steps

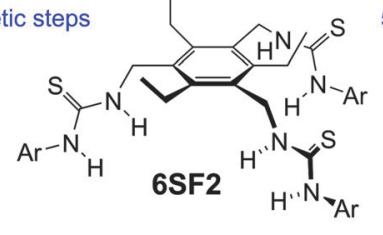

$[I]=350 \mathrm{~s}^{-1} 1$ synthetic step

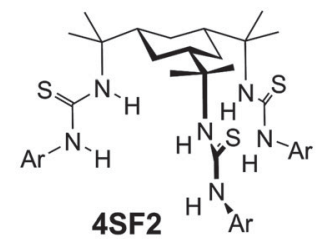

$[I]=460 \mathrm{~s}^{-1}$

5 synthetic steps

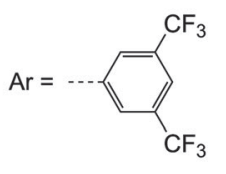

Fig. 4 A comparison of powerful anionophores reported from our laboratory. Bis-thioureidodecalin $7^{5}$ is currently the most active known. $[/]$ is a measure of chloride transport rates in $200 \mathrm{~nm}$ LUVs (see text).

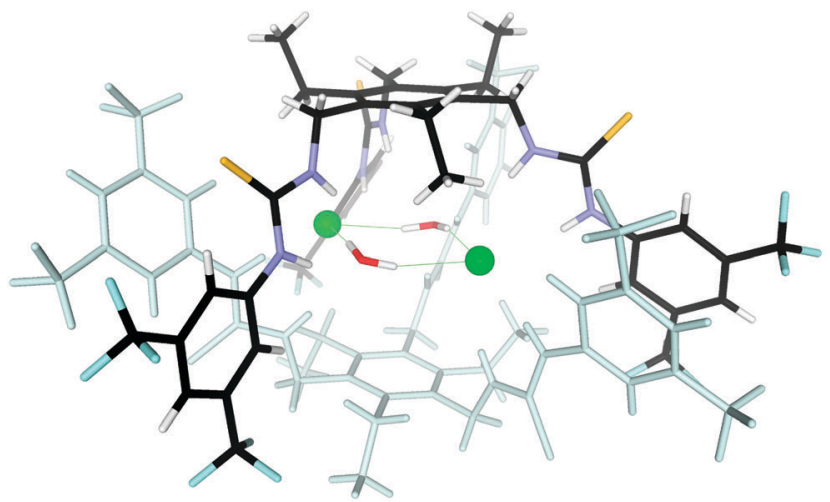

Fig. 5 Structure of $\left(6 \mathrm{SF} 2 \cdot \mathrm{Cl}^{-} \cdot \mathrm{H}_{2} \mathrm{O}\right)_{2}$ as obtained by crystallisation of $6 \mathrm{SF} 2$ $+\mathrm{Me}_{4} \mathrm{~N}^{+} \mathrm{Cl}^{-}$. One molecule of $6 \mathrm{SF} 2$ is coloured pale cyan, and the two $\mathrm{Me}_{4} \mathrm{~N}^{+}$cations outside the cavity are omitted for clarity.

Finally, the interaction of 6SF2 with chloride in the solid state was characterised by X-ray crystallography. A single crystal of $6 \mathrm{SF} 2+\mathrm{Me}_{4} \mathrm{~N}^{+} \mathrm{Cl}^{-}$was obtained by vapour diffusion of diethyl ether into a dichloromethane solution. Interestingly, two molecules of receptor were found to form a cage surrounding a cyclic $\left(\mathrm{Cl}^{-} \cdots \mathrm{H}_{2} \mathrm{O}\right)_{2}$ dianionic cluster (Fig. 5). This result raised the possibility that a dimeric species might also be responsible for transport. To clarify the issue, we measured the initial transport rates due to $\mathbf{6 S F 2}$ at five carrier loadings. The resulting doseresponse relationship was almost linear, consistent with transport by a monomeric carrier (see ESI $\dagger$ for details). The experiments also allowed us to estimate an $\mathbf{E C}_{50,270 \text { s }}$ for $\mathbf{6 S F 2}$. This measure of effectiveness, defined as the transporter loading required to achieve $50 \%$ of maximum chloride influx at $t=270 \mathrm{~s}$, is widely used in anion transport research. ${ }^{2 a}$ The value obtained for 6SF2, at $0.0019 \mathrm{~mol} \%$ carrier:lipid, is among the lowest reported in the literature (for further discussion, see ESI $\dagger$ ).

In conclusion, we have shown that sterically geared tris(thio)ureas $\mathbf{6}$ are readily synthesised in one step, and bind chloride anions with substantial affinities. The strongest receptor $\mathbf{6 S F 2}$ is a remarkably effective anionophore, given its accessibility. We believe this compound can play a useful role in anion transport research, as a powerful but readily available transmembrane anion carrier.

This work was supported by the EPSRC through the Bristol Chemical Synthesis Centre for Doctoral Training (EP/G036764/1) and research grant number EP/J00961X/1. The authors thank Pablo Ríos Moreno and Tiddo Mooibroek for a sample of triamine 5.

\section{Notes and references}

1 J. T. Davis, O. Okunola and R. Quesada, Chem. Soc. Rev., 2010, 39, 3843-3862; S. Matile, A. V. Jentzsch, J. Montenegro and A. Fin, Chem. Soc. Rev., 2011, 40, 2453-2474; N. Busschaert, C. Caltagirone, W. Van Rossom and P. A. Gale, Chem. Rev., 2015, DOI: 10.1021/ acs.chemrev.5b00099.

2 (a) P. A. Gale, R. Pérez-Tomás and R. Quesada, Acc. Chem. Res., 2013, 46, 2801-2813; (b) S.-K. Ko, S. K. Kim, A. Share, V. M. Lynch, J. Park, W. Namkung, W. Van Rossom, N. Busschaert, P. A. Gale, J. L. Sessler and I. Shin, Nat. Chem., 2014, 6, 885-892.

3 A. P. Davis, D. N. Sheppard and B. D. Smith, Chem. Soc. Rev., 2007, 36, 348-357.

4 H. Valkenier and A. P. Davis, Acc. Chem. Res., 2013, 46, 2898-2909.

5 H. Valkenier, L. W. Judd, H. Li, S. Hussain, D. N. Sheppard and A. P. Davis, J. Am. Chem. Soc., 2014, 136, 12507-12512.

6 N. Busschaert, P. A. Gale, C. J. E. Haynes, M. E. Light, S. J. Moore, C. C. Tong, J. T. Davis, J. William and A. Harrell, Chem. Commun., 2010, 46, 6252-6254; N. Busschaert, M. Wenzel, M. E. Light, P. Iglesias-Hernández, R. Pérez-Tomás and P. A. Gale, J. Am. Chem. Soc., 2011, 133, 14136-14148.

7 L. E. Karagiannidis, C. J. E. Haynes, K. J. Holder, I. L. Kirby, S. J. Moore, N. J. Wells and P. A. Gale, Chem. Commun., 2014, 50, 12050-12053.

8 B. A. McNally, A. V. Koulov, T. N. Lambert, B. D. Smith, J.-B. Joos, A. L. Sisson, J. P. Clare, V. Sgarlata, L. W. Judd, G. Magro and A. P. Davis, Chem. - Eur. J., 2008, 14, 9599-9606.

9 S. Hussain, P. R. Brotherhood, L. W. Judd and A. P. Davis, J. Am. Chem. Soc., 2011, 133, 1614-1617.

10 J. A. Cooper, S. T. G. Street and A. P. Davis, Angew. Chem., Int. Ed., 2014, 53, 5609-5613.

11 The 3-element numbering system employed herein is continued from ref. 10. The elements are scaffold (e.g. 4), atom X (e.g. S), and aryl group $\operatorname{Ar}(e . g$. F2). The aryl groups are shown in Scheme 1.

12 G. Hennrich and E. V. Anslyn, Chem. - Eur. J., 2002, 8, 2218-2224; K. J. Wallace, R. Hanes, E. Anslyn, J. Morey, K. V. Kilway and J. Siegel, Synthesis, 2005, 2080-2083.

13 M. E. Moragues, L. E. Santos-Figueroa, T. Ábalos, F. Sancenón and R. Martínez-Máñez, Tetrahedron Lett., 2012, 53, 5110-5113; G. V. Zyryanov, M. A. Palacios and P. Anzenbacher, Angew. Chem., Int. Ed., 2007, 46, 7849-7852; G. Sánchez, D. Curiel, I. Ratera, A. Tárraga, J. Veciana and P. Molina, Dalton Trans., 2013, 42, 6318-6326; A. Vacca, C. Nativi, M. Cacciarini, R. Pergoli and S. Roelens, J. Am. Chem. Soc., 2004, 126, 16456-16465; S. Roelens, A. Vacca and C. Venturi, Chem. - Eur. J., 2009, 15, 2635-2644; P. G. Young, J. K. Clegg, M. Bhadbhade and K. A. Jolliffe, Chem. Commun., 2010, 47, 463-465; N. Busschaert, L. E. Karagiannidis, M. Wenzel, C. J. E. Haynes, N. J. Wells, P. G. Young, D. Makuc, J. Plavec, K. A. Jolliffe and P. A. Gale, Chem. Sci., 2014, 5, 1118-1127.

14 For a related investigation see: W. Rakrai, N. Morakot, S. Keawwangchai, C. Kaewtong, B. Wanno and V. Ruangpornvisuti, Struct. Chem., 2011, 22, 839-847.

15 HypNMR 2008 from Hyperquad, http://www.hyperquad.co.uk/.

16 A. J. Ayling, S. Broderick, J. P. Clare, A. P. Davis, M. N. Pérez-Payán, M. Lahtinen, M. J. Nissinen and K. Rissanen, Chem. - Eur. J., 2002, 8, 2197-2203; J. P. Clare, A. J. Ayling, J. B. Joos, A. L. Sisson, G. Magro, M. N. Pérez-Payán, T. N. Lambert, R. Shukla, B. D. Smith and A. P. Davis, J. Am. Chem. Soc., 2005, 127, 10739-10746.

17 B. A. McNally, A. V. Koulov, B. D. Smith, J.-B. Joos and A. P. Davis, Chem. Commun., 2005, 1087-1089.

$18 \mathrm{Cl}^{-} / \mathrm{NO}_{3}{ }^{-}$transport by $6 \mathrm{SF} 2$ was also tested in vesicles prepared from dipalmitoylphosphatidylcholine (DPPC), which undergoes a phase transition at $41{ }^{\circ} \mathrm{C}$. No transport was observed at $25{ }^{\circ} \mathrm{C}$ (gel phase), whereas the transporter was active at $45^{\circ} \mathrm{C}$ (liquid crystalline phase), indicating a mobile carrier mechanism. See ESI $\dagger$ for details. 